\title{
АНАЛИЗ ОБРАЩЕНИЙ ГРАЖДАН В ЕВРОПЕЙСКИЙ СУД ПО ПРАВАМ \\ ЧЕЛОВЕКА ПРОТИВ \\ РОССИЙСКОЙ ФЕДЕРАЦИИ
}

\section{Б. Л. Знмненко *}

В Декларации тысячелетия ООН, утвержденной резолюцией 55/2 Генеральной Ассамблеи от 8 сентября 2000 г., было отмечено, что главы государств и правительств преисполнены решимости "Укреплять уважение к принципу верховенства права, причем как в международных, так и во внутренних делах". В этой связи защита прав и свобод человека является одним из важнейших направлений реализации данного принципа. При осуществлении национального правотворчества государства обязаны учитывать международные стандарты в области прав человека.

Как известно, в свете современного международного права защита прав человека не относится только к внутренней компетенции государства. В настоящее время имеются международные институты и механизмы, контролирующие исполнение государством своих международно-правовьх обязательств в области прав человека. Одним из таких институтов является Европейский суд по правам человека, созданный согласно Европейской конвенции о зашите прав и основньх свобод 1950 г. и рассматривающий, в частности, жалобы граждан против тех государств-участников, которые нарушают права и свободы, закрепленные Конвенцией. С 5 мая 1998 г. этот инструмент контроля стал обязательным для Российской Федерации. Данное положение полностью соответствует Конституции РФ, согласно которой "каждый вправе в соответствии с международным договором Российской Федерации обращаться в межгосударственные органы по защите прав и свобод человека, если исчерпаны все имеющиеся внутригосударственные средства правовой зацить" (ч. 3 ст. 46). 
При обращении в Суд гражданам необходимо обращать внимание на четкое соблюдение правил и выполнять все требования, предъявляемые к форме жалобы. Это наиболее важное условие на начальном этапе прохождения жалобы, поскольку от этого зависит, будет ли заявление принято к рассмотрению или нет. В российской литературе уже имеется целый ряд публикаций, разъясняющих порядок и условия обращения в Европейский суд. ${ }^{1}$

К настоящему времени Комитет Суда в составе трех судей, действующий на основании ст. 27 Конвенции, уже признал более 1500 жалоб, поданных против России, неприемлемыми. В Секретариате Суда на регистрации находятся более 1000 жалоб. Палатой Суда в составе семи судей было рассмотрено 11 жалоб против России, семь из которых признаны неприемлемыми, три жалобы - частично неприемлемыми и одна жалоба - исключена из списка в связи с дружественным урегулированием спора (ст. 39 Конвенции).

Критерии приемлемости индивидуальных жалоб сформулированы в статьях 34-35 Конвенции. Данные статьи дают ответы на следующие основные вопросы: кто имеет право обратиться в Европейский суд по правам человека? Что является "исчерпанием всех внутренних средсгв правовой защиты" и "окончательным решением по делу", принятым национальным органом? В течение какого срока лицо вправе обратиться в Суд? Обладает ли Суд компетенцией рассматривать жалобу в отношении фактов и обстоятельств, которые имели место до вступления в силу Конвенции для государства? Вправе ли гражданин обжаловать действия государства, касающиеся нарушения прав и свобод, не предусмотренных Конвенцией? Для ответа на эти вопросы в настоящей статье будет осуществлен анализ рассмотрения Судом первых жалоб против Российской Федерации, что представляет не только теоретический, но и практический интерес.

\section{Кто имеет право обращаться в Европейский суд по правам человека?}


В силу ст. 34 Конвенции "Суд может получать жалобы от любого физического лица, неправительственной организации или любой группы частных лиц, которые утверждают, что они являются жертвами нарушекия одной из Высоких Договаривающихся Сторон прав, предусмотренных положениями Конвенции и Протоколах к ней”. Ст. 34 Конвенции и судебнал практика позволякт сделать ряд важных выводов в отношении субъектов, обладающих правом обратитьсл в Европейский суд.

Во-первых, в Суд могут обращаться не только российскне граждане, но и иностранцы, утверждающие, что они явились жертвами нарушення их прав Российско Ф Федерацией. К примеру, Европейский суд принял к рассмотренкю дело против Российской Федерацин по жалобе грахданина Литвы, утверждавшего, что задержание, арест в Россин и выдача его властям Литвы было противоправным по смыслу ст. 5 Конвенции (дело № 53254/99).

Во-вторых, как следует из содержания ст. 34, в Европейский суд вправе обрацаться как физические, так и юридические лица. К примеру, в склу ст. 1 Протокола № 1 Конвенции "каждое физическое или юридическе лицо имеет право беспрепятственно пользоваться свонм имуществом". Если государство нарушило данное право, принадлежащее юридическому лицу, то последнее также может обратиться в Суд с жалобой на действия государства. По делу греческих нефтеперерабатывающих предприятий "Стрэн" и "Стратис Андреадис" в Суд обратились юридические лица, утверждавшие, что в нарушение статьи 1 Протокола № 1 Правительство Греции отказалось исполнять решение третейского суда о взыскании с него (Правительства) денежных средств в пользу нефтеперерабатывающих предприятий. ${ }^{2}$

В общем международном праве содержится норма, согласно которой государство несет международно-правовую ответственность не тольюо за действня свонх органов и должностных лиц, но и за деятельность физических и юридических лиц, находящихся под его юрнсдикцией. ${ }^{3}$ Судебная практика свидетельствует, что ког- 
да речь идет о нарушении государством прав и свобод человека, закрепленных в Конвенции, то здесь имеется в виду деятельность исключительно государственных (исполнительная, судебная, законодательная) и местных (муниципальных) властей. По делу Belvedere Alberghiera v. Italy (№ 31524/96) право беспрепятственного пользования имушеством было нарушено муниципальными властями, проложившими дорогу по территории, приналлежавшей заявителю. Применительно к России необходимо подчеркнуть, что если права и свободы человека были нарушены муниципальными властями, властями субъекта Российской Федерации или властями на федеральном уровне, то во всех этих случаях в силу ст. 34 Конвенции именно Российская Федерации, как посударство-участник, будет нести ответственность и выступать в качестве ответчика в Суде.

В этой связи нельзя не обратить внимание на то обстоятельство, что если субъектами отношений, возникших вследствие правонарушения, являются не "частное лицо - государство", а исключительно частные лица, то такое правоотношение не может быть объектом рассмотрения Европейского суда. Лицо не вправе обжаловать в Суд решение национального суда, которое разрешило спор между частными лицами. Однако, если при вынесении такого решения государством было нарушено право лица на справедливое и публичное разбирательство дела в разумный срок независимым и беспристрастным судом, созданным на основании закона (ст. 6 Конвенции), то лицо вправе обжаловать соответствующие действия государства. В этом случае предметом рассмотрения Европейского суда будет факт нарушения государством прав лица, а не решение национального органа.

Данные выводы полностью подтверждаются практикой Европейского суда. К примеру, в решении от 22 июня 1999 г. по делу $Л$. $\Phi$. Тумиловия против Россин (№ 47033/99) Суд, признавая жалобу неприемлемой, указал: “согласно ст. 34 Конвенции он (Суд) имеет дело только с жалобами, касающимися действий государства или вопросов, за которые государство несет ответственность по Конвенцин. Частные лица не могут обжаловать действия других частных лиц". 


\section{Что является "исчерпанием всех внутренних}

\section{средств правовой защиты" применительно}

к судебной системе России?

Как следует из п. 1 ст. 35 Конвенции "Суд может принимать дело к рассмотрению только после того, как были исчерпаны все внутренние средства защиты в соответствии с общепризнанными нормами международного права". Данное правило, требующее исчерпания всех внутренних средств правовой защиты до подачи жалобы в международный судебный орган, является общим принципом международного права, исходящим из убеждения в том, что государствам необходимо давать возможность исправлять ошибки, связанные с их нарушением международных обязательств, в первую очередь через национальные правовые институты.

Как известно, в Российской Федерации большинство дел, стороной в которых выступает государство, рассматриваются в судах общей юрисдикщии и арбитражньг судах. Статьи 282, 315 действующего Гражданского процессуального кодекса РСФСР (в ред. от 15 августа 2000 г.) предусматривают, что решения и определения всех судов общей юрисдикщии могут быть обжалованы в кассационном порядке. Статьи 145, 160, 161, 179 Арбитражного процессуального кодекса РФ также указывают на то, что лица, участвующие в деле, вправе подать апелляционную и кассационную жалобы на решение и определение арбитражного суда. Следовательно, в Российской Федерации "исчерпанием всех внутренних средств правовой зациты" будет считаться обращение лица в кассационную инстанцию судов общей юрисдикции или арбитражных судов и получение соответствующего судебного акта. Обращение граждан с заявлением о принесении протеста, обращение в Конституционный Суд РФ, конституционные (уставные) суды субъектов Российской Федерации не является обязательным для того, чтобы подать жалобу в Европейский суд. Данный вывод находит свое подтверждение в судебной практике.

В уже упомянутом деле $Л$. Ф. Тумиловнч протнв Россин Суд обратил внимание на то, что “жалобы заявителя в порядке надзора 
являются особыми средствами правовой защиты, использование которых зависит от дискреционных полномочий Председателя Верховного Суда РФ и заместителя Генерального прокурора РФ и, тем самым, не охватывают средства правовой защиты по смыслу п. 1 ст. 35 Конвенции".

Рассматривая данный критерий необходимо также обратить внимание на следуюшую ситуацию. Если, к примеру, лищо пропустило срок дाя обжалования решения в кассационную инстанцию и вышестоящий суд отказал ему (лицу) в удовлетворении его ходатайства - восстановлении сроков, можно ли в этом случае утверждать о том, что лицо исчерпало все внутренние средства правовой зашиты? Практика Европейского суда дает отрицательный ответ на этот вопрос.

В решении по делу Ben Salah Adraqui and others v. Spain (№ 45023/98) от 27 апреля 2000 г. Суд, прнзнавая жалобу негриемлемой, подчеркнул: "Согласно ст. 35 Конвенции Суд рассматривает дело только после того, как были исчерпаны все внутренние средства правовой защиты. В соответствин с судебной практикой данное требование считается не соблюденным, если лицо не смогло воспользоваться каким-либо средством правовой защиты вследствие нарушения им формальностей, предусмотренных законом. В данном деле иск в Конституционный Суд был отклонен в связи с нарушеннем срока, пропущенного заявителем, так как он пытался использовать иные средства правовой зашиты, не являвшиеся обязательными. В силу вышесказанного заявитель не исчерпал всех средств правовой зашиты и поэтому его жалоба признается неприемлемой".

Что является "окончательным решением по делу", принятым наднональным органом?

Как следует из п. 1 ст. 35 Конвенции лицо вправе обратиться в Суд при наличии “окончательного решения по делу”, вынесенного национальным органом. Критерий "окончательного решения по делу” непосредственно связан с критерием “исчерпанием всех внутренних средств правовой защиты". Можно говорить об оконча- 
тельном решении только тогда, когда лицом в рамках национальной правовой системы были исчерпаны все средства правовой защиты.

Требование Конвенции о наличии "окончательного решения по делу" означает то, что в момент обращения в Европейский суд данное решение, принятое вследствие исчерпания всех внутренних средств правовой защиты, не должно быть предметом рассмотрения в дальнейшем национальными органами. Если Суд установит, что в отношении окончательного решения принесен протест или, к примеру, дело было передано вышестоящим судом на новое рассмотрение в нижестоящую инстанцию суда, решение (постановление, определение) которой отменено, то жалоба заявителя будет признана неприемлемой. Данное обстоятельство ни в коей мере не означает, что лицо теряет право впоследствии обратиться в Европейский суд. После получения нового “окончательного решения по делу" гражданин вправе снова подать жалобу в Суд.

В решении от 10 октября 2000 г. по делу Н. В. Панченко протнв Россин (№ 45100/98), по которому заявитель, в частности, обжаловал незаконность его ареста, задержания, Суд подчеркнул: “определением Октябрьского районного суда Санкт-Петербурга от 13 апреля 1998 г. гражданское дело, касающееся возврата конфискованного имущества, было приостановлено до окончания судебного следствия по уголовному делу. Законность и обоснованного данного судебного акта была подтверждена определением Санкт-Петербургским городским судом от 27 мая 1998 г. Принимая во внимание, что дело было приостановлено, то есть находится в процессе судопроизводства, Суд в этой части жалобу считает неприемлемой”.

\section{В течение какого срока лицо вправе обратиться в Суд?}

В соответствии с п. 1 ст. 35 Конвенции Суд может принять дело к рассмотрению в течение шести месяцев с даты вынесения национальными органами окончательного решения по делу. Шестимесячный срок исчисляется с момента, когда оно узнало или долж- 
но было узнать о нарушении государством своего права. ${ }^{5}$ Однако, если то или иное действие государства, к примеру, не предусматривает возможности обжалования, то шестимесячный срок исчисляется с даты, когда такое действие было совершено. В решении от 17 октября 2000 г. по делу В. Каралевнкуса против Литвы и Россин (№ 53254/99), связанному с обжалованием заявителем незаконности его ареста, задержания и экстрадиции в пользу литовских властей, Европейский суд отметил: “согласно п. 1 ст. 35 Конвенции Суд может только изучить жалобу в отношении того, были исчерпаны ли все национальные средства правовой защиты, и была ли жалоба передана в пределах шести месяцев с момента вынесения национальным органом окончательного решения. В случае, отсутствия средств правовой защиты против конкретного действия государства, которое предположительно нарушает конвенционные положения, дата, когда такое действия совершилось, является моментом для исчисления шестимесячного срока" (см, также, дело Valasinas .v. Lithuania, № 44558/98, peшение or 14 марта 2000 г.).

Конвенщия не содержит возможности восстановления шестимесячного срока, пропущенного даже по уважительной причине. Поэтому, если лицо намеревается обжаловать кассацнонное постановление (определение) в порядке надзора, ему следовало бы делать это одновременно с подачей жалобы в Европейский суд. В противном случае, при отсутствии судебных актов, принятьх в порядке надзора, заявитель потеряет возможность обратится в Европейский суд из-за пропуска шестимесячного срока.

\section{Обладает ли Суд компетенцией рассматравать жалобу} В отношенин фактов и обстоятельств, которые имели место до вступления в свлу Конвенцив для государства?

Согласно общепризнанной норме международного права Европейская конвенция о защите прав человека и основных свобод не применяется к тем фактам и обстоятельствам, которые имели место до 
вступления ее в силу для государства - участника. Данное положение нашло отражение в Федеральном законе "О ратификации Конвенции о защите прав человека и основных свобод и Протоколов к ней” от 30 марта 1998 г. Как следует из ст. 1 Закона, Российская Федерация признает юрисдикцию Европейского суда обязательной по вопросам топкования и применения Конвенции и Протоколов к ней в случаях предполагаемого нарушения Российской Федерацией положений этих договорных актов, когда предполагаемое нарушение имело место после их вступления в действне для Россин. Однако указанное правило не всегда принимается во внимание лищами, апеллирующими к Европейскому суду, что приводит к признанию их жалоб неприемлемыми.

По делу Н. В. Панченко Суд отметил, что "заявитель обращается к событиям, имевшим место с апреля 1996 г, когда закончилось предварительное следствие, по 17 июля 1998 г., когда заявитель был признан судом виновным. Суд вновь подчеркивает, что он может оценивать события, состоявшиеся исключительно с 5 мая 1998 г., когда Конвенция вступила в силу для Российской Федерации. Учитывая вышеизложенное, часть жалобы, касающаяся событий, пронзошедших до 5 мая 1998 г., является вне компетенции Суда (ratione temporis) и, таким образом, неприемлемой по смыслу п. 4 ст. 35 Конвенции".

По делу В. М. Сырника против Россин (№ 44125/98), где заявитель утверждал об отсутствии эффективной правовой защиты его прав (ст. 13), в решении от 25 ноября 1999 г. Суд также обратил внимание на то, что "жалоба заявителя относится к фактам, начавшимся в 1991 г., то есть до 5 мая 1998 г. В соответствии с общепризнанным принципом международного права Конвенция обязывает государство-участника исключительно в отношении фактов, состоявшихся после вступления ее в силу".

Следовательно, если лицо в жалобе ссылается на обстоятельства, имевшие место до вступления в силу Конвенции для соответствующего государства, то такая жалоба признается Судом неприемлемой по смыслу п. 3 ст. 35 Конвенции. 
В судебное практике возник вопрос: если обстоятельства, на которые ссылается в жалобе заявитель, произошли до вступления в силу Конвенции для государства-участника, а окончательное решение по делу вынесено после указанной даты, является ли такая жалоба приемлемой? По мнению Европейского суда, в этом случае жалоба признается приемлемой.

В решении от 20 июня 2000 г. по делу O.V.R.. протнв Россин (№ 44319/98), касающемуся нарушения прав, закрепленных в статьях 11 и 14, Суд отметил, что "хотя большинство фактов и процедур, обжалуемых заявителем, предшествовало 5 мая 1998 г,, когда Конвенция стала обязательной для Российской Федерации, окончательное судебное решение было вынесено после указанной даты. Таким образом, указанное дело находится в пределах компетенции Суда".

Вправе ли гражданин обжаловать действия государства, касающиеся нарушения прав и свобод, не предусмотренных Конвенцией?

На этот вопрос необходимо сразу дать отрицательный ответ. Европейский суд рассматривает исключительно вопросы, связанные с нарушением государством-участником прав и свобод, гарантированных Конвенцией и Протоколами к ней. Если заявитель в тексте жалобы ссылается на права и свободы, не закрепленные в Конвенции (Протоколах), то такая жалоба признается неприемлемой. К сожалению, данное условие, как правило, не соблюдается гражданами России при обращении в Европейский суд.

По делу В. Черепкова против России (№ 51501/99) Суд, признавая жалобу заявителя неприемлемой, в решении от 25 января 2000 г., в том числе, указал, что требования заявителя о наличии нарушении его права, содержашегося в ст. 3 Протокола № 1, являются необоснованными, так как заявитель участвовал в муниципальных выборах мэра, а ст. 3 гарантирует участие в выборах законодательной власти, которая согласно Конституции РФ принадлежит Государственной Думе и Совету Федерации. 
По вышеупомянутому делу В. Каралевикуса заявитель, в частности, обращал внимание Суда на нарушение его прав, закрепленных в ст. 3 Конвенции, запрещающей подвергать какого-либо пыткам и бесчеловечному или унижающему достоинство обращению или наказанию. Заявитель, апеллируя к ст. 3, также сослался на многочисленные нарушения, допушенные государством при переводе его из одного тюремного учреждения в другое. Суд, признавая жалобу частично неприемлемой, подчеркнул, что "статья 3 Конвенции не гарантирует права лица избирать тюремное учреждение, где бы он хотел находиться под стражей".

По делу Д. Лукашт против Россин (№ 48041/99) заявитель, вовремя не предоставивший в экзаменационную комиссию справку об инвалидности, не смог поступить на общих основаниях на юридический факультет Санкт-Петербургского университета. Судебные инстанции установили необоснованность его требований. Заявитель полагал, что государство нарушило его право на образование, предусмотренное ст. 2 Протокола № 1 Конвенции. Суд, признавая жалобу неприемлемой, в решенин от 16 ноября 1999 г. отметил, что “ в любом случае статья 2 Протокола № 1 допускает ограниченный прием в учебные заведение только тех, кто удачно сдал вступительные экзамены. Более того, заявитель, не сдавший экзамены в СанктПетербургский университет, не был лишен возможности поступить в другое высшее учебное заведенне".

Большое количество жалоб, находящихся в Секретариате Суда, касаются несвоевременной выплаты государством пенсионных пособий. Европейский суд рассматривает такие действия государства как нарушение ст. 1 Протокола № 1 Конвенции. Поэтому, если несвоевременная выплата пенсии имела место после вступления Конвенции в силу для Российской Федерации и при соблюдении иных критериев приемлемости, то заявители имеют хорошие шансы на удовлетворение своих требований. Так произошло в деле Ю. Тайков против Россин. 
Заявитель, обратившийся 6 января 1999 г. в Суд, утверждал, что государство с 1995 г. несвоевременно выплачивает ему пенсию по старости, все его иски к государственным органам социального обеспечения остались без удовлетворения. Европейский суд 28 марта 2000 г., руководствуясь п. 1 ст. 37 Конвенция, принял решение об исключении жалобы из списка подлежащих рассмотрению дел в связи с заключением заявителем соглашения с государством, согласно которому последнее обязалось выплатить заявителю 93898 рублей за период с августа 1995 по август 1999 г.

Рассматривая дело, Европейский суд анализирует национальные правовые нормы, судебную практику для определения, насколько они соответствуют конвенционным положениям. Однако в резолютивной части решения Суд только констатирует факт, имелось ли нарушение государством положений Конвенций или нет. Суд не может признать тот или иной внутригосударственный нормативный акт или решение суда противоречащим Конвенции, так как это не входит в его компетенцию. Вследствие этого Суд не может обязать государство внести изменения в национальное законодательство или отменить соответствующее решение национального суда. В противном случае такие действия Суда могли быть расценены как вмешательство во внутренние дела государства. Это положение также должно учитываться лицами, обращающимися в Суд.

В мотивировочной части решения по делу Carbonara and Ventura v. Italy от 30 мая 2000 г. (№ 24638/94) Европейский суд подчеркнул, что "применение Кассационным Судом Италии нормы о пятилетнем сроке, в течение которого бывшие собственники не могли требовать от государства возмещения убытков, явилось вмешательством в право беспрепятственного пользования имуществом, несовместимым со статьей 1 Протокола № 1 Конвенции". Однако в резолютивной (постановочной) части Суд указал исключительно на факт нарушения государством соответствующей нормы Конвенции.

Учитывая первый опыт рассмотрения дел против Российской Федерации, необходимо предпринимать меры, направленные на по- 
вышение правовой культуры российских граждан в сфере современного международного права. Адвокаты, перед тем как составить жалобу в Европейский суд по правам человека, должны ознакомиться не только с текстом Конвенции, но и практикой применения Судом соответствующих конвенционных положений, их толкования. Значимость решений Европейского суда обусловливается, в частности, и тем обстоятельством, что при рассмотрении дел Суд для аргументации своей позиции нередко ссылается на ранее принятые им решения и в этой связи можно говорить о прецедентном праве Европейского суда. К примеру, в решении от 30 мая 2000 г. по делу $A O$ v. Italy (№ 22534/93) Суд сослался на решения от 28 сентября 1985 года по делу Spadea and Scalabrino v. Italy и от 28 июля 1999 г. по делу Immobiliare Saffi v. Italy (№22774/93).

* Кандидат кридических наук, член Московской городской коллегии адвокатов. В настояшей статье приводятся примеры некоторых решений Европейского суда по правам человека с офицнального сайта Суда: www.dhcour.coe, раздел "Judgements and decisions". Найти необходимое решение Суда можно с помощью поисковой системы "the case-law collection(s) system", которая также находится на официальном сайте Европейского суда.

1 См., напр.: В.А. Карташкин, Как подать жалобу в Европейский Суд по правам человека, М., Норма, 2000; А.М. Зрделевский, Обращение в Европейский Суд, М., Юристь, 1999 и др.

2 Европейский Суд по правам человека. Нзбранные решения, М., Норма, 2000, т. 2, с. 54-68.

3 Лукашук Н. И., Международное право. Общая часть, М., Бек, 1997, с. 180.

4 Речь идет не о третейских, а о государственных арбитракных судах Российской Федерации.

5 См. Д. Гомьен, Д. Харрис, Л. Зваак, Европейская конвенция о правах человека и Европейская социальная хартия: право и практика, М., Издательство Московского независимого института международного права, 1998, с. 77-78. Необходимо отметить, что данная книга написана с учетом работы контрольного механизма Европейского суда, действовавшего до 1 ноября 1998 г. В связи с принятием Протокола № 11 Конвенции в настоящее время функционирует новый контрольный механизм Суда. В частности, сейчас отсутствует Европейская комиссия по правам человека.

6 Более подробно см.: Европейская конвенция о правах человека и Европейская социальная хартия: право и практика, с 77 социальная хартия: право и практика 